\title{
CONHECIMENTO TRADICIONAL SOBRE PIRACEMA E DEFESO DA PESCA EM DUAS COMUNIDADES DA ÁREA DE PROTEÇÃO AMBIENTAL DA BAIXADA MARANHENSE, BRASIL
}

\section{TRADITIONAL KNOWLEDGE ABOUT SPAWNING SEASON (PIRACEMA) AND CLOSED FISHING IN TWO COMMUNITIES OF PROTECTED AREA OF THE BAIXADA MARANHENSE, BRAZIL}

DANTAS, Janaina Gomes janabio23@hotmail.com

Universidade Estadual do Maranhão Secretaria de Estado de Meio Ambiente e Recursos Naturais do Maranhão

\author{
ANDRADE, Ticianne de Sousa de Oliveira Mota \\ ticiannedeoliveira@gmail.com \\ Universidade Estadual do Maranhão \\ Secretaria de Estado de Meio Ambiente \\ e Recursos Naturais do Maranhão \\ NETA, Raimunda Nonata Fortes Carvalho \\ raifortes@gmail.com \\ Universidade Estadual do Maranhão \\ JUNIOR, Audalio Rebelo Torres \\ audalio.torres@gmail.com \\ Universidade Federal do Maranhão
}

\begin{abstract}
RESUMO O conhecimento tradicional é uma sabedoria popular acumulada pela prática de atividades em ambientes naturais. Pautado nisto, diagnosticou-se a composição da ictiofauna de importância econômica e o período da piracema e do defeso da pesca em dois municípios do Maranhão. Entrevistas semiestruturadas com pescadores artesanais permitiram caracterizar 19 espécies de importância econômica. Bem como, indicaram uma comunidade que tem a pesca como ofício principal e afirma não pescar no período do defeso; e uma comunidade onde a pesca é uma atividade secundária e acontece de forma ininterrupta ao longo do ano. Tais informações são necessárias para subsidiar ações de Educação Ambiental e medidas de manejo que aliem a conservação dos recursos naturais à manutenção das comunidades tradicionais.
\end{abstract}

Palavras-chave: Gestão de recursos naturais. Pescadores artesanais. Seguro desemprego.

ABSTRACT Traditional knowledge is a popular wisdom accumulated by the practice of activities in natural environments. In view of this, It was diagnosed the composition of the fish fauna of economic importance and the period of spawning season (piracema) and the fishing closure in two municipalities of Maranhão. Semi-structured 


\section{Atos de Pesquisa em Educação - ISSN 1809-0354 \\ Blumenau, v. 12, n.3 p.641-659, mai./ago. 2017 \\ DOI: http://dx.doi.org/10.7867/1809-0354.2017v12n3p641-659}

interviews with artisanal fishermen allowed the characterization of 19 species of economic importance. As well, the interviews indicated a community that has fishing as main craft and who say not to fish in the closed fishing period; and a community where fishing is a secondary activity and which is uninterrupted throughout the year. This information is necessary to support environmental education and management measures that combine conservation of natural resources with the maintenance of traditional communities.

Keywords: Artisanal fishermen. Management of natural resources. Unemployment Insurance.

\section{INTRODUÇÃO}

A pesca artesanal no rio Mearim (maior bacia hidrográfica do Maranhão) apresenta grande importância socioeconômica em função, principalmente, do grande potencial pesqueiro existente e da relação de dependência das comunidades tradicionais por esta atividade.

A pesca comercial e de subsistência nessa região (atualmente caracterizada como Área de Proteção Ambiental) acontecia durante todos os meses do ano, não havendo um calendário de pesca baseado no período reprodutivo dos peixes. Quando não existiam regras formais para a gestão pesqueira, a pesca artesanal seguia um calendário de atividades determinado pela abundância dos recursos pesqueiros nas diferentes épocas do ano (KALIKOSKI et al. 2002).

Essas regras de pesca eram baseadas na experiência dos pescadores locais e, como tal, representavam uma forma de conhecimento ecológico tradicional, com consequências importantes para a manutenção da pesca artesanal, criando limites naturais para a exploração desses recursos de uso comum (KALIKOSKI et al. 2002). Com a escassez dos recursos pesqueiros e o advento de legislação ambiental mais restritiva, a pesca foi proibida (época conhecida como período do "defeso" da pesca) em algumas regiões em determinados períodos do ano, época em que ocorre a desova de muitas espécies de peixes, moluscos e crustáceos (BRASIL, 1991; IBAMA, 2003).

Segundo Lourenço, Henkel e Maneschy (2006), o seguro-defeso é um benefício definido a partir da inclusão plena dos trabalhadores rurais no sistema previdenciário oficial. Isso ocorreu com a promulgação da Lei n. ${ }^{\circ} 8.213$, de 25 de 


\section{Atos de Pesquisa em Educação - ISSN 1809-0354 \\ Blumenau, v. 12, n.3 p.641-659, mai./ago. 2017 \\ DOI: http://dx.doi.org/10.7867/1809-0354.2017v12n3p641-659}

julho 1991, que incluiu os pescadores artesanais entre os segurados especiais, considerados aqueles que, "individualmente ou em regime familiar", fazem da pesca sua "profissão habitual ou principal meio de vida", desde que respeitadas algumas outras características (BRASIL, 1991).

A Portaria do Instituto Brasileiro de Meio Ambiente e Recursos Naturais Renováveis (IBAMA) $n^{\circ} 85$, de 31 de dezembro de 2003, no seu Art. $1^{\circ}$, proíbe, anualmente, de $1^{\circ}$ de dezembro a 30 de março, o exercício da pesca de qualquer categoria e modalidade, e com qualquer petrecho, nas bacias hidrográficas dos rios Pindaré, Maracaçumé, Mearim, Itapecuru, Corda, Munim, Turiaçu, Flores, Balsas e Grajaú, bem como, em igarapés, lagos, barragens e açudes públicos do Estado do Maranhão (IBAMA, 2003). Portanto, no rio Mearim, o defeso totaliza quatro meses. É nesse período que tem direito ao seguro desemprego o pescador artesanal afiliado e considerado apto a recebê-lo.

A implementação de um período de defeso como medida de gestão deve atender a pré-requisitos como a proteção de períodos reprodutivos e a redução de esforço de pesca. Com o estabelecimento desse período, o pescador artesanal adquiriu o direito ao recebimento do seguro desemprego durante a pausa na atividade pesqueira para a preservação das espécies (CONTATO, 2012). Dessa forma, trabalhos que visam a verificar se tais objetivos têm sido alcançados se tornam de extrema relevância e atuam como ponto de partida para a melhoria das estratégias de proteção dos ambientes e recursos naturais sem impactar também as comunidades tradicionais que dependem diretamente deles.

O Conhecimento Ecológico Tradicional pode ser um grande aliado para proteção de habitats e espécies econômicas e culturalmente importantes, além de colaborar para o planejamento de medidas voltadas à conservação da biodiversidade nas áreas alagáveis (SILVA \& MORAES, 2010). Esse conhecimento tradicional pode ser investigado a partir das percepções ambientais das diferentes comunidades. A percepção ambiental foi indicada pela Organização das Nações Unidas para a Educação, a Ciência e a Cultura - UNESCO (1973) e pela legislação brasileira ligada a áreas protegidas (BRASIL, 2000) como um dos aspectos determinantes para o planejamento ambiental, visto que uma das dificuldades para a 


\section{Atos de Pesquisa em Educação - ISSN 1809-0354 \\ Blumenau, v. 12, n.3 p.641-659, mai./ago. 2017 \\ DOI: http://dx.doi.org/10.7867/1809-0354.2017v12n3p641-659}

proteção dos recursos naturais está na existência de diferentes percepções sobre os valores e a importância dos ambientes entre os indivíduos de diferentes culturas ou de grupos sociais que desempenham funções distintas em áreas de importância ecológica.

A pesquisa em percepção ambiental tem sido utilizada por gestores e organizações ligadas à administração de áreas protegidas no Brasil e apresenta-se como uma ferramenta que auxilia nos processos decisórios com a garantia da participação das comunidades envolvidas com as Unidades de Conservação criadas no país (BARROS, 2013). Portanto, neste estudo, objetivou-se diagnosticar a composição da ictiofauna de importância econômica e o período da piracema e do defeso da pesca nos municípios de Vitória do Mearim e Arari (municípios pertencentes à Área de Proteção Ambiental da Baixada Maranhense) com base na percepção de duas comunidades de pescadores artesanais.

\section{MATERIAL E MÉTODOS}

No presente estudo, foram aplicados questionários em duas comunidades pesqueiras, com o intuito de obter informações dobre piracema e defeso da pesca. A metodologia indica informações sobre as duas áreas estudadas e os procedimentos utilizados para o desenvolvimento da pesquisa.

\section{1 ÁREA DE ESTUDO}

Os municípios de Arari e Vitória do Mearim fazem parte da Área de Proteção Ambiental (APA) da Baixada Maranhense e estão inseridos na bacia hidrográfica do rio Mearim que ocupa uma área de $99.058,68 \mathrm{Km}^{2}$, sendo a maior bacia genuinamente maranhense com $29,84 \%$ da área total do estado (ANA, 2005), envolvendo 83 municípios, dos quais, 65 possuem sedes localizadas dentro dela, segundo dados do Instituto Brasileiro de Geografia e Estatística (IBGE, 2000). Nos dois municípios existem muitas comunidades que apresentam grande dependência da pesca, como exemplo, Curral da Igreja que está localizado a $10 \mathrm{~km}$ do Município de Arari; nesta localidade, o número estimado de moradores é de 186 habitantes 
Atos de Pesquisa em Educação - ISSN 1809-0354

Blumenau, v. 12, n.3 p.641-659, mai./ago. 2017

DOI: http://dx.doi.org/10.7867/1809-0354.2017v12n3p641-659

(IBGE, 2010). Já o povoado conhecido como Engenho Grande fica a $5 \mathrm{~km}$ de Vitória do Mearim e sua população é estimada em 56 habitantes (IBGE, 2010).

\subsection{PROCEDIMENTOS}

Assim como Ramires et al. (2012), o contato inicial com os pescadores das comunidades foi feito por meio de visitas informais nas residências, com o intuito de esclarecer os objetivos do trabalho, conhecer as famílias, identificar o número de pescadores residentes e solicitar a assinatura de um termo de consentimento livre e esclarecido autorizando a utilização dos resultados para comunicação a outros pesquisadores e publicação de dados em revistas científicas.

Por meio de questionários semiestruturados que enfocavam aspectos relacionados à piracema e ao período de defeso da pesca, foram entrevistados 19 moradores do povoado Engenho Grande e 18 moradores do povoado Curral da Igreja.

Os táxons citados pelos entrevistados foram comprados em mercados locais e identificados por meio dos trabalhos de Higuchi (2013), Piorski et al. (2007), Piorski et al. (1998), utilizando informações contidas na página virtual FishBase (http://www.fishbase.org/search.php). A análise de dados foi descritiva, com base, principalmente, no número de citações feitas pelos pescadores. O tratamento dos dados foi realizado conforme a metodologia adotada por Silva \& Gonçalves (2012).

\section{RESULTADOS E DISCUSSÃO}

Considerando que o conhecimento do pescador local é fonte de informações para gerar estudos básicos sobre a biologia reprodutiva da ictiofauna local, os resultados do presente estudo estão fundamentados no conhecimento tradicional sobre pesca e na legislação que estipula o período do defeso para a bacia hidrográfica do Mearim, visando contribuir com informações que servirão como ponto de partida para ações de Educação Ambiental e para a melhoria das 


\section{Atos de Pesquisa em Educação - ISSN 1809-0354 \\ Blumenau, v. 12, n.3 p.641-659, mai./ago. 2017 \\ DOI: http://dx.doi.org/10.7867/1809-0354.2017v12n3p641-659}

estratégias de gestão pesqueira na Área de Proteção Ambiental da Baixada Maranhense. Segue os resultados obtidos.

\subsection{CARACTERIZAÇÃO DAS COMUNIDADES}

O perfil etário dos entrevistados (homens e mulheres) variou de 28 a 79 anos (com uma média de 53 anos), no povoado de Engenho Grande, e de 23 a 75 anos (com uma média de 51 anos), em Curral da Igreja. O ingresso de indivíduos mais jovens na atividade pesqueira pode estar relacionado ao interesse no seguro defeso, ou ainda devido às limitadas possibilidades de emprego ou de continuidade dos estudos. Esses dados são semelhantes ao que foi registrado no Rio Grande do Sul por Garcez \& Sánchez-Botero (2005) em seus estudos realizados nos municípios visitados à margem do Rio Uruguai, Santa Vitória do Palmar e São José do Norte.

A participação feminina foi bem representativa em ambas as comunidades, correspondendo a 47\% (Engenho Grande) e 50\% (Curral da Igreja), o que indica uma força de trabalho importante no cenário pesquisado. Tais mulheres têm uma rotina dividida entre tarefas domésticas e o trabalho na pesca.

Segundo Silva (2009), nas comunidades pesqueiras interiorizadas, a pesca é ainda uma importante atividade econômica que as mulheres exercem lado a lado com os companheiros, impondo nova ordem no trabalho e culturalmente redefinindo os papéis. Deduz-se que o resultado do trabalho feminino na faina da pesca acrescido ao do companheiro eleva a renda e dá para prover o sustento familiar (SILVA, 2009).

Os resultados relacionados com a participação comunitária nas atividades ligadas ao estabelecimento do período do defeso da pesca e fiscalização permitiram identificar diferenças entre as duas comunidades pesqueiras investigadas (Tabela 1). A maioria dos moradores da Comunidade de Engenho Grande afirma que participou de reuniões para elaboração do período do defeso no rio Mearim. Todavia, no povoado Curral da Igreja, a maioria das pessoas não pertence a nenhum tipo de associação de classe e apenas um pequeno percentual afirma ter 


\section{Atos de Pesquisa em Educação - ISSN 1809-0354 \\ Blumenau, v. 12, n.3 p.641-659, mai./ago. 2017 \\ DOI: http://dx.doi.org/10.7867/1809-0354.2017v12n3p641-659}

participado de reuniões sobre seguro defeso. Ser ou não membro da colônia de pescadores provoca resultados variados na vida do pescador.

De acordo com Maldonado \& Santos (2011), a colônia de pescadores pode atuar como uma instituição que Ihes traz benefícios (seguro-desemprego e outras seguridades sociais), como objeto de críticas em razão das dificuldades passadas, ou ainda como reconhecimento de um grupo que a integra. Tocantins et al. (2011) afirmam que a Colônia tem como função dar suporte aos pescadores, organizando questões de documentação para o período da piracema.

Entretanto, Santos \& Santos (2005) destacam que o nível de organização e de integração social entre os pescadores está aquém do necessário para legitimar os seus anseios, no tocante a aspectos como linhas de financiamento, assistência técnica, infraestrutura, entre outras necessidades. Esses autores destacam, ainda, que essa postura precisa ser alterada, pois, no contexto atual, as reivindicações das necessidades conjuntas passam, obrigatoriamente, pela capacidade de organização e articulação da classe. Assim, com o fortalecimento da organização e do capital social dentro da categoria, maiores benefícios poderiam ser obtidos.

Tabela 1. Dados comparativos das duas comunidades pesqueiras entrevistadas na Baixada Maranhense.

\begin{tabular}{lcc}
\hline \multicolumn{1}{c}{ Situação investigada } & Curral da lgreja (\%) & Engenho Grande (\%) \\
\hline 1) Participação em reunião para a & $22 \%$ & $63 \%$ \\
elaboração do período do defeso no & & \\
Mearim. & & $56 \%$ \\
2) Afiliação em colônia de & $22 \%$ & $50 \%$ \\
pescadores ou sindicato. & $28 \%$ & \\
3) Presenciou uma fiscalização do & & \\
IBAMA.
\end{tabular}

Fonte: Elaborado pelos autores.

\subsection{PERCEPÇÃO SOBRE A DIFERENÇA EXISTENTE ENTRE PIRACEMA E SEGURO DEFESO}

O meio ambiente pode ser percebido pelas pessoas de várias formas e, geralmente, alguns fatores influenciam na relação da percepção de diferentes 


\section{Atos de Pesquisa em Educação - ISSN 1809-0354 \\ Blumenau, v. 12, n.3 p.641-659, mai./ago. 2017 \\ DOI: http://dx.doi.org/10.7867/1809-0354.2017v12n3p641-659}

comunidades, o que pode gerar respostas diferenciadas entre indivíduos de uma mesma comunidade (LOPES e GUEDES, 2013). O estudo da percepção ambiental serve de base para a melhor compreensão das interações entre o homem e o ambiente, suas expectativas, satisfações e insatisfações, julgamentos e condutas (ZAMPIERON et al., 2003). Partindo deste pressuposto, os entrevistados foram questionados sobre as definições e diferenças entre piracema e defeso (Tabela 2).

A maioria dos entrevistados respondeu satisfatoriamente quanto à definição de piracema, relacionando-a com a atividade reprodutiva dos peixes. Contudo, identificou-se certa falta de conhecimento das duas comunidades sobre a relação existente entre piracema e defeso, já que alguns entrevistados associaram piracema com a proibição de pesca. Além disso, nenhum dos entrevistados afirmou saber o que é "defeso". Diante disto, torna-se evidente a necessidade de atividades educativas nessas comunidades, enfatizando os aspectos relacionados com o período reprodutivo dos peixes e a legislação proibitiva da pesca nas diferentes bacias hidrográficas do Estado do Maranhão ao longo do ano.

Conforme informações do IBAMA (2003), durante o período da piracema nas bacias hidrográficas do Maranhão é permitida apenas a pesca de subsistência, desembarcada e praticada de maneira artesanal por populações ribeirinhas que precisam garantir a alimentação familiar. Mesmo assim, a Portaria IBAMA $n^{\circ} 85$, de 31 de dezembro de 2003, diz que os ribeirinhos devem respeitar a cota diária de cinco quilogramas por pescador ou um exemplar de qualquer peso, desde que esteja no tamanho mínimo de captura (IBAMA, 2003). Segundo Carvalho (2002), para alguns pescadores, ir ao rio para pescar $5 \mathrm{~kg}$ é o suficiente para comer, mas não cobre as despesas com a pesca. Como não há outro trabalho disponível para o qual tenham qualificação, muitos saem para pescar e trazem aquilo que foi capturado, às vezes ultrapassando a quantia de pescado permitida.

É importante destacar que nas comunidades estudadas a referida portaria, ao longo dos anos, tem sido interpretada de forma errônea. Nas entrevistas realizadas com as duas comunidades pesqueiras e com a colônia de pescadores de Vitória do Mearim, registrou-se que os pescadores entendem que o permitido na pesca durante o período do defeso é "cinco quilogramas de peixe por pescador mais 01 


\section{Atos de Pesquisa em Educação - ISSN 1809-0354 \\ Blumenau, v. 12, n.3 p.641-659, mai./ago. 2017 \\ DOI: http://dx.doi.org/10.7867/1809-0354.2017v12n3p641-659}

(um) exemplar de qualquer peso". Na verdade, a legislação determina que se pode capturar diariamente cinco quilogramas de peixe ou um exemplar de grande peso; mas nunca os dois casos (IBAMA, 2003). Dessa forma, pela interpretação equivocada da lei, os pescadores entrevistados podem ser considerados infratores no período do defeso da pesca em sua região, incorrendo nas penalidades previstas na legislação, que podem ir de multa até detenção, sem mencionar os danos aos recursos pesqueiros que podem ter sido ocasionados ao longo dos últimos anos.

Tabela 2. Dados comparativos das respostas dos entrevistados sobre piracema e defeso.

\begin{tabular}{|c|c|c|c|c|}
\hline \multicolumn{2}{|r|}{ Afirmações } & Engenho Grande & Curral da Igreja & Citações dos entrevistados \\
\hline 1) & $\begin{array}{l}\text { Definiram piracema } \\
\text { como período de } \\
\text { reprodução. }\end{array}$ & $50 \%$ & $44 \%$ & $\begin{array}{c}\text { Piracema é a época que o } \\
\text { peixe tá desovando nos } \\
\text { igarapés. }\end{array}$ \\
\hline 2) & $\begin{array}{l}\text { Definiram piracema } \\
\text { como período de } \\
\text { proibição. }\end{array}$ & $33 \%$ & $17 \%$ & $\begin{array}{c}\text { Na época da piracema não } \\
\text { pode pescar, só para consumo. }\end{array}$ \\
\hline 3) & $\begin{array}{l}\text { Piracema e defeso é } \\
\text { a mesma coisa. }\end{array}$ & $17 \%$ & - & $\begin{array}{c}\text { Piracema e defeso é proteção } \\
\text { dos peixes. }\end{array}$ \\
\hline 4) & $\begin{array}{l}\text { Não sabem o que é } \\
\text { piracema. }\end{array}$ & - & $39 \%$ & - \\
\hline & TOTAL & $100 \%$ & $100 \%$ & \\
\hline
\end{tabular}

Fonte: Elaborado pelos autores.

\subsection{ATIVIDADES REALIZADAS DURANTE O PERÍODO DO SEGURO DEFESO}

Conforme Santos \& Santos (2005), a dedicação à atividade pesqueira é um item importante para saber se a pesca supre a necessidade dos pescadores. Diante disto, averiguou-se que outras atividades são realizadas pelos pescadores da região, principalmente, no período de defeso da pesca, já que neste momento o esforço de pesca deve ser reduzido significativamente.

Em Engenho Grande, pode-se distinguir uma maior parte dos pescadores que têm a pesca como principal exercício e que afirmam não pescar no período do defeso, a não ser a quantia permitida. Entre as ocupações secundárias desenvolvidas estão lavoura/agricultura (23\%), quebra de coco babaçu $(23 \%)$ e 


\section{Atos de Pesquisa em Educação - ISSN 1809-0354 \\ Blumenau, v. 12, n.3 p.641-659, mai./ago. 2017 \\ DOI: http://dx.doi.org/10.7867/1809-0354.2017v12n3p641-659}

comércio (18\%). Contudo, deve-se avaliar com cuidado as atitudes destes pescadores frente ao período de defeso, pois na comunidade identificaram-se alguns pescadores que, apesar de terem se associado há algum tempo, ainda não possuem suas carteiras, estando impossibilitados de receber o seguro defeso. Observações feitas por Carvalho (2002) enfatizam que no período do defeso, os pescadores recebem o equivalente a um salário mínimo. No entanto, o benefício em geral não é pago mensalmente durante esse período, e há pescadores que só recebem ao fim dos três meses de pesca interditada.

Em Curral da Igreja, 47\% afirmam que continuam pescando no período do defeso. A maioria tem a pesca como atividade secundária, afirmando que só pescam para consumo próprio, já quem exerce principalmente outras ocupações econômicas, como por exemplo, a lavoura/agricultura (23\%). Segundo Garcez \& Sánchez-Botero (2005), durante o período de defeso, são buscadas alternativas econômicas, como serviços temporários sem carteira de trabalho assinada para não se perder o seguro desemprego.

Contudo, nas comunidades estudadas, percebeu-se que durante o ano, a maior parte da renda dos entrevistados vem a partir de outras atividades realizadas (sem carteira assinada), e a maioria dos entrevistados se autodenominam de pescadores profissionais somente para manter a oportunidade de receber o seguro defeso. E como muitos destes afirmam realizar a pesca de subsistência, ou seja, destinada à sua alimentação e à de seus familiares, a pesca acontece de maneira ininterrupta ao longo do ano. Assim, como Ramires et al. (2012) destacaram, é importante observar que, apesar da existência de outras atividades econômicas, a pesca artesanal é desenvolvida diariamente pelos pescadores e fornece a principal fonte de proteína para o consumo das famílias e para a venda, nas comunidades estudadas.

\subsection{TAMANHOS DE CAPTURA DAS PRINCIPAIS ESPÉCIES DE INTERESSE COMERCIAL}

Semelhante aos resultados do estudo desenvolvido por Ramires et. al. (2012), a ictiofauna capturada nas duas comunidades foi caracterizada qualitativamente por 


\section{Atos de Pesquisa em Educação - ISSN 1809-0354 \\ Blumenau, v. 12, n.3 p.641-659, mai./ago. 2017 \\ DOI: http://dx.doi.org/10.7867/1809-0354.2017v12n3p641-659}

meio das informações dos pescadores, resultando numa listagem composta por 19 espécies pertencentes a 19 gêneros e 12 famílias de peixes citadas como as mais comuns, sendo curimatá (Prochilodus nigricans e Prochilodus lineatuas) o táxon com o maior número de citações (Tabela 3).

Tabela 3. Ictiofauna citada pelos pescadores de Engenho Grande e Curral da Igreja (APA da Baixada Maranhense).

\begin{tabular}{|c|c|c|c|}
\hline $\begin{array}{c}\text { Espécies citadas } \\
\text { (Nome popular) }\end{array}$ & $\begin{array}{c}\text { Citação das espécies } \\
\text { nas entrevistas }\end{array}$ & Família & Nome científico \\
\hline Curimatá & $12 \%$ & Prochilodontidae & $\begin{array}{c}\text { Prochilodus nigricans e } \\
\text { Prochilodus lineatus }\end{array}$ \\
\hline Pirapema & $5 \%$ & Megalopidae & Megalops atlanticus \\
\hline Traíra & $9 \%$ & Erythrynidae & Hoplias malabaricus \\
\hline Corró & $7 \%$ & Doradidae & Platydoras costatus \\
\hline Mandi & $11 \%$ & Pimelodidae & Pimelodus blochii \\
\hline Piranha & $10 \%$ & Characidae & Pygocentrus nattereri \\
\hline Surubim & $11 \%$ & Pimelodidae & Pseudoplastystoma fasciatum \\
\hline Pescada & $2 \%$ & Sciaenidae & Plagioscion squamosissimus \\
\hline Bagre & $9 \%$ & Ariidae & Hexanematichthys couma \\
\hline Capadinho & $5 \%$ & Auchenipteridae & Trachelyopterus galeatus \\
\hline Tubajara & $7 \%$ & Pimelodidae & Sorubim lima \\
\hline Bodó & $1 \%$ & Loricariidae & Liposarcus pardalis \\
\hline Jeju & $2 \%$ & Erythrinidae & Hoplerythrinus unitaeniatus \\
\hline Branquinha & $1 \%$ & Curimatidae & Potamorhina altamazonica \\
\hline Aracu & $2 \%$ & Anostomidae & Schizodon vittatus \\
\hline Sardinha & $1 \%$ & Characidae & Triportheus angulatus \\
\hline Piaba & $1 \%$ & Characidae & Astyanax bimaculatus \\
\hline Tapiaca & $1 \%$ & Curimatidae & Curimata cyprinoides \\
\hline Choradeira & $1 \%$ & Curimatidae & Psectrogaster amazonica \\
\hline
\end{tabular}

Fonte: Elaborado pelos autores.

Conforme informações divulgadas pelo Ministério da Pesca e Aquicultura (2014), o tamanho mínimo de captura refere-se ao tamanho a partir do qual é permitida a pesca de um determinado táxon, baseado no tamanho da primeira maturação sexual da espécie e é implantado com o intuito de assegurar a correta 


\section{Atos de Pesquisa em Educação - ISSN 1809-0354 \\ Blumenau, v. 12, n.3 p.641-659, mai./ago. 2017 \\ DOI: http://dx.doi.org/10.7867/1809-0354.2017v12n3p641-659}

conservação e gestão da atividade pesqueira. No caso de haver captura de exemplares de dimensões inferiores ao tamanho mínimo estabelecido é obrigatória a sua imediata devolução ao ambiente aquático. Segundo Agostinho et al. (2005), o controle da pesca procura regular a captura de peixes jovens (comprimento mínimo de captura e tamanho mínimo de malha) e proteger locais de desova durante o período reprodutivo. Porém, essas medidas são comprometidas pela falta de informações sobre as populações de peixes, de recursos financeiros e pelo limitado poder de fiscalização. Diante disso, averiguou-se o conhecimento local sobre o tamanho mínimo permitido para a captura de peixes.

Os resultados obtidos indicaram um paradoxo, pois $67 \%$ do total de entrevistados afirmou conhecer o tamanho mínimo de captura permitido para as espécies da região, mas a maioria das explicações relata o peso $(\mathrm{em} \mathrm{kg})$ do peixe (e não o seu tamanho em $\mathrm{cm}$ ) para definir o tamanho mínimo de captura. Além disso, muitos pescadores usam as expressões "pequeno", "grande", "um palmo" (para o tamanho mínimo de cada espécime capturado), indicando o desconhecimento sobre os tamanhos mínimos dos peixes que podem ser pescados. Esses dados indicam que a atual estratégia utilizada pelos cientistas e gestores ambientais não tem sido satisfatória para orientar a pesca de modo a garantir a continuidade dos estoques pesqueiros. Segundo Godinho (2007), há espécies que atingem a maturidade sexual apenas após alcançarem um grande tamanho corporal; por outro lado, há espécies que, mantidas sob determinadas condições, aceleram o processo de maturidade e atingem a fase reprodutiva ainda com tamanho reduzido.

Os entrevistados ainda foram questionados se deixariam de comercializar peixes pequenos e peixes pescados no período do defeso e da piracema se isto fosse aumentar a quantidade de peixes no rio. Nas duas comunidades, a maioria dos entrevistados (89\% em Engenho Grande e 78\% em Curral da Igreja) afirmou que deixaria de pescar e de comercializar peixes pequenos se isso fosse eficaz para aumentar os estoques. Tal cenário indica a predisposição das comunidades pesqueiras para a realização de um trabalho conjunto com os órgãos gestores ambientais, tais como as recomendações propostas por Costa (2006) em seu estudo no município de Viana (também pertencente à APA da Baixada Maranhense). Nessa 


\section{Atos de Pesquisa em Educação - ISSN 1809-0354 \\ Blumenau, v. 12, n.3 p.641-659, mai./ago. 2017 \\ DOI: http://dx.doi.org/10.7867/1809-0354.2017v12n3p641-659}

pesquisa de Costa (2006), recomenda-se uma maior atuação do poder público municipal com o intuito de promover a capacitação e organização dos pescadores valorizando a sustentabilidade da atividade; assim como a implementação do papel técnico da colônia de pescadores de forma a orientar maneiras mais produtivas de pescar, armazenar e comercializar; e por fim, desenvolver programas de educação ambiental permanentes com as comunidades pesqueiras visando à sustentabilidade desses recursos e dos ambientes explorados.

As informações obtidas nas duas comunidades pesqueiras investigadas na Baixada Maranhense são úteis para a gestão dos recursos pesqueiros da região. Concordamos com as ideias de Ramires et al. (2012) quando afirmam que acessar tais percepções, extrair comprovações científicas e torná-las social e cientificamente acessíveis, é uma alternativa para propostas de manejo e conservação de ecossistemas ainda pouco utilizada pela ciência. Assim, as informações obtidas nas comunidades pesqueiras de Arari e Vitória do Mearim nos permitem sugerir uma revisão quanto aos ensinamentos e exigências no que se refere ao tamanho mínimo permitido para captura dos peixes, podendo ser substituído pelo peso $(\mathrm{kg})$ mínimo permitindo, já que conforme comprovado, os pescadores demonstraram ter maior afinidade e entendimento com este tipo de medida.

\subsection{ATITUDES TOMADAS FRENTE AOS PEIXES CAPTURADOS NO PERÍODO DE REPRODUÇÃO}

As comunidades foram questionadas sobre quais são suas atitudes quando capturam peixes ovados (tabela 4). Em Engenho Grande, a maioria declarou devolver o peixe para o rio, enquanto que em Curral da Igreja ocorreu o inverso, possivelmente, devido ao fato de "ovas de peixe" ser um prato muito apreciado na comunidade (conforme afirmações de muitos moradores da região).

Houve um número representativo de entrevistados, em ambas as comunidades, que afirmou que a devolução ou não dos peixes depende de alguns fatores como o tamanho do espécime. Segundo eles, a devolução dos peixes só ocorre em alguns casos, por exemplo, se o peixe for muito pequeno e se for possível a visualização das ovas, como é o caso do peixe viola, que segundo os próprios 


\section{Atos de Pesquisa em Educação - ISSN 1809-0354 \\ Blumenau, v. 12, n.3 p.641-659, mai./ago. 2017 \\ DOI: http://dx.doi.org/10.7867/1809-0354.2017v12n3p641-659}

pescadores incuba seus ovos na boca, estando desta forma visível, permitindo a sua devolução ao rio.

De acordo com Santos \& Santos (2005), alguns fundamentos científicos e a própria percepção cultural do pescador são suficientes para indicar o período de desova como o momento mais apropriado para aplicação das leis de defeso. Afinal, o período de desova corresponde ao ápice da vida dos reprodutores, quando eles estão gerando novos seres semelhantes a si mesmos e quando seu estado fisiológico inspira cuidados.

Tabela 4. Atitudes dos entrevistados das comunidades pesqueiras de Vitória do Mearim e Arari referentes à pesca de peixes em período reprodutivo.

\begin{tabular}{lccc}
\hline Situação & Engenho Grande & Curral da Igreja & Citações dos entrevistados \\
\hline Devolve ao rio & $37 \%$ & - & - \\
Não devolve ao rio & $31 \%$ & $58 \%$ & Gosto de comer ova de peixe; \\
Depende & $32 \%$ & $42 \%$ & Solto o peixe viola porque guarda a \\
& & & ova na boca; Quando é grande \\
& & como, quando é pequeno devolvo \\
& & para o rio. \\
\hline
\end{tabular}

Fonte: Elaborado pelos autores.

Sabendo-se que o consumo de peixes em período reprodutivo e a retirada deles do habitat comprometem os estoques pesqueiros, os dados apresentados nesta pesquisa indicam a necessidade de ações educativas com as comunidades de pescadores estudadas. As ovas de Curimatá, por exemplo, são muito apreciadas em diversas regiões do nordeste. No Rio grande do Norte, ovas de várias espécies de peixes são apreciadas na culinária regional (SILVA et al., 2014) e algumas são conhecidas como "caviar do sertão". Dessa forma, um aspecto educativo a ser considerado nas comunidades pesqueiras da Baixada Maranhense deve voltar-se para a sensibilização da população sobre os costumes locais de se consumir "peixes ovados".

Tais ações de educação ambiental precisam atingir a comunidade em geral, pois a procura por espécies nestas condições (ovadas) incentiva a pesca ilegal desses organismos. Sugere-se pautar tais ações educativas em um modelo de 


\section{Atos de Pesquisa em Educação - ISSN 1809-0354 \\ Blumenau, v. 12, n.3 p.641-659, mai./ago. 2017 \\ DOI: http://dx.doi.org/10.7867/1809-0354.2017v12n3p641-659}

gestão compartilhada; Kalikoski et al. (2008) apresentam como uma estratégia participativa e flexível de gestão, que propicia e mantém um fórum para ação na participação, criação de regras, manejo de conflitos, compartilhamento do poder, liderança, diálogo, tomada de decisões, negociação, geração e compartilhamento de conhecimento, aprendizagem e desenvolvimento entre os usuários dos recursos, outros atores e o governo. A gestão compartilhada é o processo consensual de reconhecer os diferentes valores, necessidades, preocupações e interesses envolvidos no manejo de um recurso.

\section{CONCLUSÃO}

A ictiofauna de importância econômica do Rio Mearim citada pelas comunidades entrevistadas foi caracterizada em 19 espécies, sendo curimatá (Prochilodus nigricans e Prochilodus lineatuas) o táxon mais representativo no cenário local. Dessa forma, sugere-se o estudo da biologia reprodutiva e o estudo populacional destas espécies para avaliar as condições e níveis de preservação deste importante recurso para as comunidades estudadas.

A maioria dos pescadores das duas comunidades estudadas compreende que piracema é um processo natural que ocorre anualmente e consiste na migração dos peixes rio acima, onde encontram condições adequadas para a sua reprodução. Todavia, os pescadores não conseguiram relacionar essas informações com o "seguro defeso", que é um seguro desemprego destinado ao pescador artesanal para suprir suas necessidades sociais (quando ficam impossibilitados de pescar) e para estimular a conservação dos recursos pesqueiros. Perante esse quadro, urge a elaboração de políticas públicas adequadas às necessidades das comunidades pesqueiras, que possam colaborar, efetivamente, para melhorar a qualidade de vida dos ribeirinhos e garantir a continuidade da ictiofauna do rio Mearim.

\section{AGRADECIMENTOS}

Gostaríamos de agradecer às comunidades Engenho Grande e Curral da Igreja pela cessão das informações; aos discentes do curso de Ciências Biológicas 
Atos de Pesquisa em Educação - ISSN 1809-0354

(Departamento de Química e Biologia da UEMA) e do curso de Ciências/Biologia (Programa Darcy Ribeiro, Polo de Arari, UEMA), ao Mestrado em Recursos Aquáticos e Pesca da UEMA e à Universidade Federal do Maranhão pela colaboração durante o trabalho de campo; e à Fundação de Amparo à Pesquisa e ao Desenvolvimento Cientifico e Tecnológico do Maranhão (FAPEMA) pelo suporte financeiro, através do edital REBAX Nº 30/2013.

\section{JANAINA GOMES DANTAS}

Mestre em Recursos Aquáticos e Pesca pela Universidade Estadual do Maranhão UEMA (2015). Atual Superintendente de Biodiversidade e Áreas Protegidas da Secretaria de Estado de Meio Ambiente e Recursos Naturais do Maranhão.

\section{TICIANNE DE SOUSA DE OLIVEIRA MOTA ANDRADE}

Mestre em Recursos Aquáticos e Pesca pela Universidade Estadual do Maranhão UEMA (2016). Atual Superintendente de Gestão de Resíduos do Estado do Maranhão.

\section{RAIMUNDA NONATA FORTES CARVALHO NETA}

Doutora em Biotecnologia (RENORBIO/UECE). Professora (adjunto III) da Universidade Estadual do Maranhão- UEMA. Coordenadora do Curso de Mestrado em Recursos Aquáticos e Pesca (PPGRAP/UEMA), docente permanente do mestrado em Oceanografia (UFMA) e colaboradora do Mestrado em Biodiversidade, Ambiente e Saúde (UEMA). Atual diretora do Curso de Ciências Biológicas e chefe do Laboratório de Biomarcadores em Organismos Aquáticos (LABOAq/UEMA),

\section{AUDALIO REBELO TORRES JUNIOR}

Doutor em Engenharia Oceânica pela Universidade Federal do Rio de Janeiro (2005). Professor da Universidade Federal do Maranhão (UFMA). Professor colaborador do Instituto Alberto Luiz Coimbra de Pós-Graduação e Pesquisa de Engenharia.

\section{REFERÊNCIAS}

Agência Nacional de Águas (ANA). Brasília. 2005. Panorama do Enquadramento dos Corpos d'Água. Estudo Técnico de Apoio ao Plano Nacional de Recursos Hídricos. Disponível em: <http://www.ana.gov.br/pnrh_novo/Tela_Apresentacao.htm> Acesso em: 09 Set. 2014. 
Atos de Pesquisa em Educação - ISSN 1809-0354

Blumenau, v. 12, n.3 p.641-659, mai./ago. 2017

DOI: http://dx.doi.org/10.7867/1809-0354.2017v12n3p641-659

AGOSTINHO, A. A.; THOMAZ, S. M.; GOMES, L. C. Conservação da biodiversidade em águas continentais do Brasil. Megadiversidade, v. 1, n. 1, p. 70-78, 2005.

BARROS, J. R. A percepção ambiental dos quilombolas kalunga do engenho e do vão de almas acerca do clima e do uso da água. Ateliê Geográfico, v. 6, n. 4, p. 216236, 2013.

BRASIL. Lei n 8.213 de 24 de julho de 1991. Brasília, DF: 1991. Disponível em: <http://www.ipsm.mg.gov.br/arquivos/legislacoes/legislacao/leis/lei_8213.pdf> Acesso em 08 Set. 2014.

BRASIL, Lei № 9.985 de 18 de julho de 2000. Regulamenta o art. 225, § 1o, incisos I, II, III e VII da Constituição Federal, institui o Sistema Nacional de Unidades de Conservação da Natureza e dá outras providências. Publicada no Diário Oficial da União em Brasília em 18 de julho de 2000. Disponível em:

<http://www.planalto.gov.br/ccivil_03/leis//9985.htm>. Acesso em 28 de set. 2012.

CARVALHO, A. R. Conhecimento ecológico tradicional no fragmento da planície de inundação do alto rio Paraná: percepção ecológica dos pescadores. Acta Scientiarum, v. 24, p. 573-580, 2002.

CONTATO, M. C. D. O período de defeso na manutenção dos meios de vida e na gestão da pesca artesanal no Município de Rio Grande - RS. 2012. $81 \mathrm{f}$.

Dissertação (Mestrado em Geografia: Área de Concentração em Análise Ambiental)

- Universidade Federal de Rio Grande - FURG, Rio Grande (RS), 2012.

COSTA, C. L. Sustentabilidade da pesca artesanal no Lago de Viana, Área de Proteção Ambiental da Baixada Maranhense. 2006. 104 f. Dissertação (Mestrado em Sustentabilidade de Ecossistemas) - Universidade Federal do Maranhão - UFMA, São Luis (MA), 2006.

FISHBASE. Disponível em: <http://www.fishbase.org/> Acesso em: 01 out. 2014.

GARCEZ, D. S.; SÁNCHEZ-BOTERO; J. I. Comunidades de pescadores artesanais no estado do Rio Grande do Sul, Brasil. Atlântica, Rio Grande, v. 27 , n.1, p. 17-29, 2005.

GODINHO, H. P. Estratégias reprodutivas de peixes aplicadas à aquicultura: bases para o desenvolvimento de tecnologias de produção. Revista Brasileira de Reprodução Animal, Belo Horizonte, v.31, n.3, p.351-360, 2007.

INSTITUTO BRASILEIRO DE GEOGRAFIA E ESTATÍSTICA (IBGE). 2000.

Disponível em:

<http://www.ibge.gov.br/home/estatistica/populacao/atlas_saneamento/pdfs/mappag 99.pdf> Acesso em: 09 Set. 2014. 
Atos de Pesquisa em Educação - ISSN 1809-0354

INSTITUTO BRASILEIRO DE GEOGRAFIA E ESTATÍSTICA (IBGE). 2010

Disponível em: <http://cidades.ibge.gov.br/xtras/perfil.php?lang=\&codmun=210100> Acesso em: 09 set. 2014.

INSTITUTO BRASILEIRO DE MEIO AMBIENTE E RECURSOS NATURAIS RENOVÁVEIS (IBAMA). Portaria $n^{\circ} 85$, de 31 de dezembro de 2003. Disponível em: <http://www.icmbio.gov.br/cepsul/images/stories/legislacao/Portaria/2003/p_ibama_8 5_2003_defesobaciashidrograficas_ma_vigindo_p_ibama_9_2004.pdf> Acesso em $0 \overline{8}$ set. $\overline{2} 014$.

HIGUCHI, H. Sobre a nomenclatura científica e classificação adotadas. In: SOARES, E. C. Soares, E. C. (Org.) Peixes do Mearim. 10 ed. São Luís - MA: Instituto Geia, 2013. p. 37-131.

KALIKOSKI, D.C.; VASCONCELLOS, M. C. \& LAVKULICH, L. Fitting institutions to ecosystems: the case of artisanal fisheries management in the estuary of Patos Lagoon. Marine policy, v. 26, n.3, p. 179-196, 2002.

KALIKOSKI, D.; DIAS NETO, J., RUFFINO, M. L., \& MARRUL FILHO, S. Gestão compartilhada do uso sustentável de recursos pesqueiros: refletir para agir. Brasília: IBAMA, 2008.

LOURENÇO, C.; HENKEL, J. A. \& MANESCHY, M. C. A. A Seguridade Social para os Pescadores Artesanais no Brasil: estudo de caso no Pará. Coletivo Internacional de Apoio aos Trabalhadores da Pesca-ICFS. 2006.

LOPES, R. B.; GUEDES, J. A. Percepção Ambiental dos pescadores no município de Macaíba - RN. Ateliê Geográfico, v. 7, n. 3, p.149-163, 2013.

MALDONADO, F.; SANTOS, A. C. Cooperativas de pescadores artesanais: uma análise sob a perspectiva teórica. Organizações Rurais \& Agroindustriais, v. 8, n. 3, p. 323-333, 2011.

Ministério da Pesca e Aquicultura (MPA). Tamanho Mínimo de Captura. Disponível em:<http://www.mpa.gov.br/images/Docs/Pesca/Tabela\%20tamanhos\%20mínimos\% 20completa.pdf > Acesso em: 26 nov. 2014.

RAMIRES, M. et al. A pesca e os pescadores artesanais de Ilhabela (SP), Brasil. Boletim do Instituto de Pesca, v. 38, n. 3, p. 231 - 246, 2012.

SILVA, C. J. D. \& MORAIS, F. F. D., Conhecimento ecológico tradicional sobre fruteiras para pesca na Comunidade de Estirão Comprido, Barão de MelgaçoPantanal Matogrossense. Biota Neotropica, v. 10, n. 3, p. 197-203. 2010. 
SILVA, A. F. Pesca artesanal: seu significado cultural. Ateliê Geográfico, v. 3, n. 1, p.132-149, 2009.

SILVA, E. F., OLIVEIRA, J. E. L.; SCHIAVETTI, A. Conhecimento ecológico local (CEL) na pesca artesanal da Reserva de Desenvolvimento Sustentável Estadual Ponta do Tubarão-RN, Brasil. Boletim do Instituto de Pesca, v. 40, n. 3, p. 355-375, 2014.

PIORSKI, N. M.; CASTRO, A. C. L.; SOUSA-NETO, A. M. Ichtyofauna from the Cerrado of the southern Maranhão. In: BARRETO, L. (Org.). North Cerrado of Brazil. Pelotas, RS: USEB, 2007, p. 197-212.

PIORSKI, N. M. et al. Ictiofauna do trecho inferior do rio Itapecuru, Nordeste do Brasil. Boletim do Laboratório de Hidrobiologia, v. 11, p. 15-24. 1998.

SANTOS, G. M.; SANTOS, A. C. M. Sustentabilidade da pesca na Amazônia. Estudos avançados, v.19, n.54, p. 165-182, 2005.

SILVA, D. C. F.; GONÇALVES, A. A. Perfil de consumo de pescado dos usuários do restaurante universitário da UFERSA. Revista Caatinga, v. 25, n. 3, p. 125-129. 2012

TOCANTINS, N.; ROSSETTO, O. C.; BORGES, F. R. Abordagem socioeconômica dos pescadores filiados à colônia Z11: Município de Poconé, pantanal de Mato Grosso, Brasil. Revista Geográfica de América Central, Número Especial EGAL, p. 1-9. 2011.

United Nations Educational Scientific and Cutural Organization - UNESCO. The training of functional literacy personnel: a practical guide: a method of training for development. UNESCO: Paris, 1973.

ZAMPIERON, S. L. M.; FAGIONATO, S.; RUFINO, P. H. P. Ambiente, representação social e percepção. In: SCHIEL, D.; MASCARENHAS, S.; VALERIAS, N.; SANTOS, S. A. M. (Orgs.). O estudo de bacias hidrográficas: uma estratégia para educação ambiental. 2 ed. São Carlos: RiMA. 2003. Cap.1, p.24-27. 